\title{
MÉTODOS DIRETOS E INDIRETOS PARA O REGISTRO DE MAMÍFEROS NO FRAGMENTO DE MATA ATLÂNTICA - UNIVAP, CAMPUS URBANOVA
}

\author{
Caio Ferreira ${ }^{1}$ \\ Douglas Pereira Lima Gomes ${ }^{2}$ \\ Karla Andressa Ruiz Lopes ${ }^{3}$ \\ Nádia Maria Rodrigues de Campos Velho ${ }^{4}$
}

Resumo: A Mata Atlântica é um dos biomas mais ameaçados do Brasil e o estabelecimento de áreas protegidas é uma das formas para se conservar este bioma. Para legalizar uma unidade de conservação, é preciso conhecer a fauna e flora local. O trabalho objetiva inventariar a mastofauna terrestre em um fragmento de Mata Atlântica, localizado na divisa entre os municípios de Jacareí e São José dos Campos, SP. Foram utilizados dois métodos distintos: método direto (transecto linear) e método indireto (parcela de areia). Como resultados foram registrados oito táxons distribuídos em quatro ordens: Cingulata, Carnivora, Didelphimorphia e Rodentia. Os dois métodos foram eficientes para o registro da mastofauna presente na área de estudo.

Palavras-chave: Rastros; Vestígios; Mastofauna; Floresta Atlântica; Transecto Linear.

\footnotetext{
${ }^{1}$ Centro de Estudos da Natureza/Universidade do Vale do Paraíba, Brasil. E-mail: cfvision09@gmail.com. 2 Centro de Estudos da Natureza/Universidade do Vale do Paraíba, Brasil. E-mail: douglasplgomes@yahoo.com.br.

${ }^{3}$ Centro de Estudos da Natureza/Universidade do Vale do Paraíba, Brasil. E-mail: alopes.karla@gmail.com.

${ }^{4}$ Centro de Estudos da Natureza/Universidade do Vale do Paraíba, Brasil. E-mail: nvelho@univap.br.
} 